\title{
Model Agribisnis Impatien Balsamina Sebagai Penggerak Perekonomian Pedesaan dan Pelestarian Budaya Lokal di Bali
}

\author{
Ni Putu Sukanteri' ${ }^{1}$, Pande Komang Suparyana ${ }^{2}$, I Ketut Widnyana ${ }^{3}$, \\ I Putu Fajar Kartika Lestari ${ }^{1}$ \\ ${ }^{1}$ Prodi Agribisnis, Fakultas Pertanian dan Bisnis, Universitas Mahasaraswati Denpasar \\ ${ }^{2}$ Prodi Agribisnis, Fakultas Pertanian, Universitas Mataram \\ ${ }^{3}$ Prodi Agroteknologi, Fakultas Pertanian dan Bisnis Universitas Mahasaraswati \\ Denpasar \\ ${ }^{1}$ putusukanteri@unmas.ac.id
}

\begin{abstract}
Impatien balsamina flower is one of the agricultural products of rural communities as an agribusiness product that has economic and cultural values. The purpose of this study was to determine the profit, profit sharing and marketing margin of Impatien Balsamina agribusiness, to find out the benefits of Impatien Balsamina flowers in preserving local culture in community activities. daily. The impatient model of balsamina agrbinis research was conducted in Sibang Village, Mengwi District, Badung Regency. This study involved 25 respondents consisting of farmers, marketers and consumers of impatien balsamina flowers. The data analysis method used in this research is the analysis of farmer share and marketing margin of impatien balsamina flower. As well as the economic benefits and its role in preserving local culture which is reflected in everyday life. The results showed that the impatien balsamina flower marketing model involved farmers, village collectors, large collectors, retailers and consumers. The highest profit of agribinis impatiens balsamina interest is obtained by agribinis actors in channel III, namely retailers with an average flower sale of $\mathrm{Rp} \mathrm{11,500} \mathrm{per} \mathrm{kg}$. The farmer's share of the research shows that the average share received by the farmer is $120 \%$ if the farmer sells it to collectors in the village. And the biggest marketing margin is obtained in marketing channel III. Impatien balsamina flowers as a means of ceremony in the local culture of the Balinese people.
\end{abstract}

Keywords: Impatien Balsamina; Agribusiness; Local Culture

\begin{abstract}
Abstrak
Bunga impatien balsamina merupakan salah satu hasil usahtani masyarakat pedesaan sebagai salah satu produk agribisnis bernilai ekonomis dan bernilai budaya.Tujuan penelitian yaitu untuk mengetahui keuntungan, famer's share dan marjin pemasaran agribinis Impatien Balsamina, untuk mengetahui manfaat bunga impatien balsamina dalam pelestarian budaya local pada kegiatan masayarakat sehari-hari. Penelitian model agrbinis impatien balsamina dilaksanakan di Desa Sibang, Kecamatan mengwi Kabupaten Badung. Penelitian melibatkan 25 reponden terdiri dari petani, pemasar dan konsumen bunga impatien balsamina. Metode analisis data yang digunakan dalam penelitian yaitu analisis famer's share dan margin pemasaran terhadap bunga impatien balsamina. Serta manfaatnya secara ekonomi s dan perannya dalam pelesatarian budaya local yang tercermin dalam kehidupan sehari-hari. Hasil penelitian menunjukkan bahwa model pemasaran bunga impatien balsamina melibatkan petani, pengepul desa, pengepul besar, pengecer dan konsumen. keuntungan agribinis bunga impatiens balsamina paling tinggi diperoleh oleh pelaku agribinis pada saluran III yaitu pengecer rata-rata
\end{abstract}


sebesar Rp 11.500 per kg penjualan bunga. Famer's share yang dihasilkan dari penelitian menunjukkan bahwa share yang diterima petani rata-rata $120 \%$ jika petani menjual di pedagang pengumpul di Desa. Dan margine pemasaran yang diperoleh paling besar pada saluran pemasaran III. Bunga impatien balsamina sebagai sarana upacara dalam budaya lokal masyakarat di Bali.

Kata Kunci: Impatien Balsamina; Agribisnis; Budaya Lokal.

\section{Pendahuluan}

Produk pertanian merupakan produk basis kehidupan masyarakat. Basis kehidupan masyarakat dilihat dari perekonomian dan pelestarain budaya lokal. Seiring dengan kemajuan teknologi berbagai kemudahan dapat dilakukan dalam upaya meningkatkan perekonomian masayarakat. Bunga pacar air merupakan salah satu jenis bunga yang mempuyai potensial yang cukup tinggi (Munir et al., 2021). Pertanian pedesaan saat ini masih menghadapi tiga masalah besar, yaitu lemahnya modal sosial, kemiskinan dan kerusakan sumberdaya pertanian yang semakin membesar sehinga perlu dilakukan pergiliran pola tanam untuk memperoleh manfaat yang lebih besar (Pranadji, 2004).

Salah satu komoditas agribinis yang dapat dijadikan sebagai sumber perputaran perekonomian masyarakat yaitu agribinis Impatien Balsamina. Selain sebagai sumber pendapatan usahatani, juga di gunakan sebagai sarana pelestarin budaya local yang dapat diwujudkan dalam bentuk fisik yaitu pembuatan canang.

Permintaan bunga impatiens Balsamina mengalami fluktuasi peningkatan pada waktu hari raya, menjadikan kesempatan bagi petani dalam memperoleh pendapatan yang lebih tinggi. Terjadi pergeseran untuk pengeluaran ritual dari konsumsi tersier menjadi konsumsi sekunder bahkan cenderung ke konsumsi primer, hal ini membuat permintaan komoditas sarana pelengkap upacara Agama Hindu menjadi meningkat (P K Suparyana et al., 2017).

Impatiens Balsamina L dibudidayakan petani sebagai substitusi dari usahatani padi karena dapat dipanen hampir setiap hari dan sebagai salah satu pendukung pelestarian budaya local karena dapat digunakan sebagai sara upacara. Menurut Lim (2014), bunga impatien balsamina, banyak ditanam di kebun dan telah dinaturalisasi sebagai tanaman budidaya di daerah tropis dan subtropics.

Tujuan penelitian yaitu untuk mengetahui keuntungan, famer's share dan marjin pemasaran agribinis Impatien Balsamina, untuk mengetahui manfaat bunga impatien balsamina dalam pelestarian budaya local pada kegiatan masayarakat sehari-hari.

\section{Metode}

Lokasi penelitian dilakukan di Desa Sibang Gede sebagai basis usahatani Impatiens Balsamina L, Pasar Kreneng sebagai pemasaran Impatien Balsamina. Pemilihan sampel dipilih sebanyak masing masing 10 orang petani, 2 orang pedagang di tingkat Desa, 3 Orang pedagang Besar di Pasar dan 10 orang konsumen sebagai narasumber dalam penelitian ini yang telah berkecipung dalam agribisnis Impatien Balsamina lebih dari 15 tahun.

Data primer dalam penelitian ini meliputi harga impatien Balsamina di tingkat petani, di tinggat pedang dan di tingkat konsumen. Data skunder dalam penelitian ini meliputi data produksi, kegunaan impatien balsamina. Pengukuran variable dalam penelitian ini meliputi: 1) Harga di tingkat petani, 2) Harga di tingkat pedagang Desa, 3) Harga di tingkat pedagang Besar di Pasar, 4) Harga di tingkat Pengecer, 5) Harga di tingkat konsumen. 
Untuk mengukur famer's share, marjin dan keuntungan dapat dilihat pada formula di bawah ini:

1. Marjin Pemasaran

Margin pemasaran, bagian harga yang diterima petani pada masing-masing saluran pemasaran (Istiyanti, 2010). Margin pemasaran merupakan salah satu indikator yang digunakan untuk menentukan efisiensi (Wulandari et al., 2018).

$\mathrm{Mp}=\mathrm{Pr}-\mathrm{Pf}$

Keterangan:

$\mathrm{Mr}=$ Marjin Pemasaran

$\operatorname{Pr}=$ harga ditingkat pedagang/pengecer

Pf = harga ditingkat petani

2. Biaya Pemasaran

$\mathrm{Bp}=\mathrm{Bp} 1+\mathrm{Bp} 2+\mathrm{Bp} 3+\ldots .+\mathrm{Bpn}$

Keterangan:

$\mathrm{Bp}=$ Biaya Pemasaran $(\mathrm{Rp} / \mathrm{Kg})$

$\mathrm{i}=1,2,3 \ldots \mathrm{N}$

$\mathrm{n} \quad=$ Jumlah lembaga pemasaran

3. Keuntungan Pemasaran

Selanjutnya untuk mengetahui besarnya profit marjin setiap lembaga pemasaran digunakan rumus:

$\mathrm{P}=\mathrm{Mr}-\mathrm{C}$

Keterangan:

$\mathrm{P} \quad=$ Keuntungan

$\mathrm{Mr}=$ Marjin Pemasaran

$\mathrm{C}$ = Biaya Pemasaran

\section{Hasil dan Pembahasan}

\section{Gambaran Umum Daerah Penelitian}

Penelitian dilaksanakan di Desa Sibang Gede, Kecamatan Abiansemal, Kabupaten Badung. Pemilihan lokasi dilakukan secara sengaja dengan pertimbangan hampir $80 \%$ masyarakat di Desa Sibak menanam Impatien Balsamina sebagai komoditas usahatani yang bernilai ekonomis, sebagai sarana upakara dalam budaya lokal.

\section{Model Pemasaran Impatien Balsamina}

Pemasaran impatien Balsamina dilakukan oleh banyak pelaku pasar, yang dapat dilihat pada gambar 1. Berdasarkan hasil penelitian dapat diketahui bahwa terdapat beberapa pelaku yang terlibat dalam pemasaran bunga impatien Balsamina. Adapun pihak yang terlibat yaitu panen bunga yang dihasilkan petani di kumpulkan pada pengepul desa, Pengepul desa ini adalah orang-orang yang membeli hasil panen petani secara langsung dan mengumpulkan di desa, selanjutnya menjual ke pasar-pasar terdekat. Atau pengepul desa ini ada yang menjual langsung kepada pengepul besar atau pengecer. Sehingga pengepul desa hampir tidak bersentuhan langsung dengan konsumen akhir. 


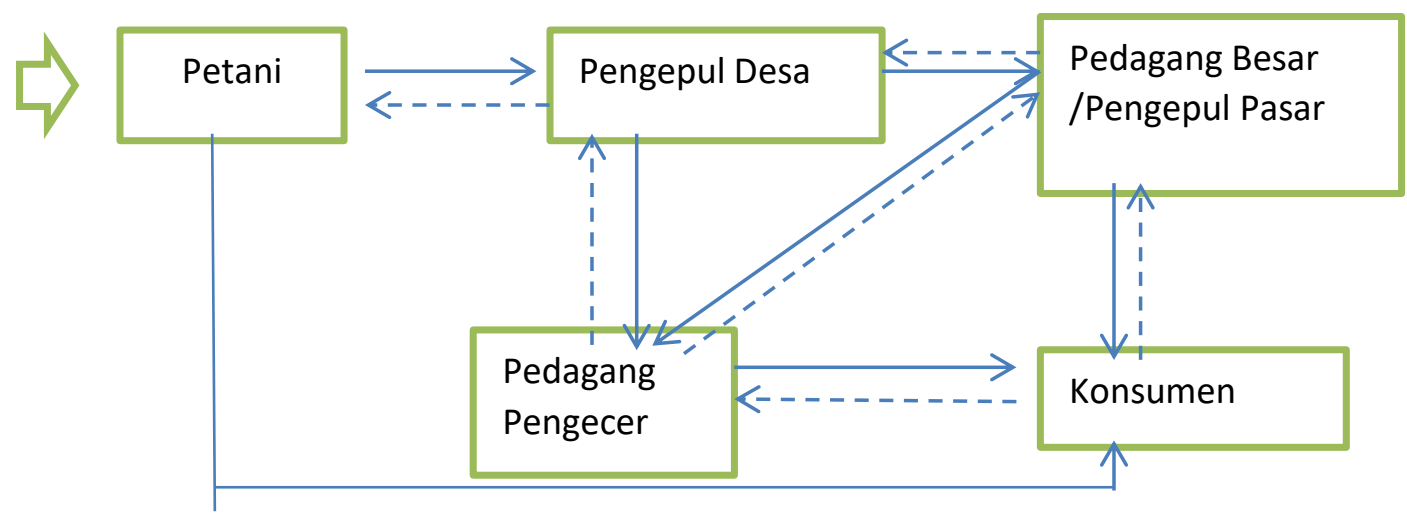

Gambar 1. Model Pemasaran Bunga Impatien Balsamina

Terdapat pihak pedagang besar yang terlibat dalam pemasaran bunga impatien balsamina. Pedagang besar ini atau pengepul pasar hanya menerima bunga yang dijual oleh pengepul desa selanjutnya pedagang besar menjual ke pengecer yang menjual secara langsung kepada konsumen. Pedagang besar tidak bersentuhan langsung dengan pengepul besar dan jarang melayani penjualan kepada konsumen dengan volume yang kecil. Peran pengepul besar ini sekaligus sebagai jembatan bagi pengecer-pengecer yang menjual bunga kepada konsumen dalam volume kecil atau menjual ke pedagang canang.

Pedagang pengecer berperan menjual bunga ke konsumen langsung yang menggunakan bunga sebagai kebutuhan sehari hari sebagai sarana upakara. Pedagang pengecer ada yang membeli langsung dari pengepul desa, karena pedagang pengecer akan memperoleh harga yang lebih murah dibandingkan dengan membeli pada pengepul besar dan penjualan kepada konsumen sesuai dengan harga pasar.

\section{Agribisnis Impatien Balsamina L Sebagai Penggerak Perekonomian di Pedesaan}

Bunga Impatien Balsamina dibudidayakan oleh petani di lahan sawah sebagai tanaman horti yang dapat dimanfaatkan sebagai tanaman bernilai ekonomis. Bunga Impatien Balsamina merupakan bunga yang dibudidayakan petani yang dapat dipanen setiap hari dengan nilai per kg mampu melebihi harga padi per kg. Aditya et al., (2017), menunjukkan bahwa bunga impatien balsamina diproduksi guna memenuhi kebutuhan dan mendapat pasar setiap hari bagi produknya. Proses budidaya impatien balsamina dapat dilihat pada Gambar 2.

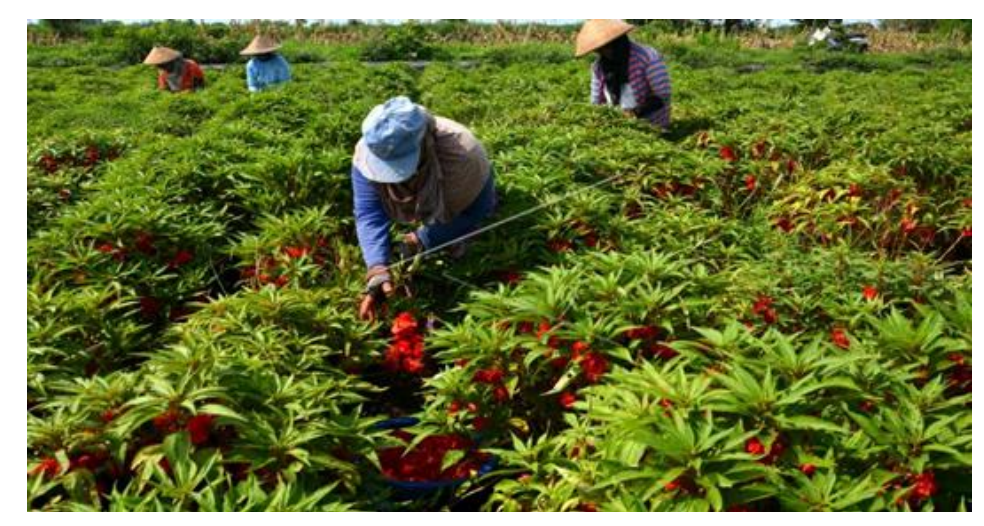

Gambar 2. Budidaya impatien balsamina di lahan sawah 
Agribinis yang dimaksud yaitu Agribisnis merupakan suatu sistem yang terdiri dari sub sistem, dari mulai pengadaan sarana produksi sampai pemasaran hasil. Sebagai produk agribinis bunga impatiens balsamina yang dibutuhkan setiap hari oleh masayarakat. Sebagai tanaman yang menghasilkan bunga yang tidak tahan lama maka bunga ini memberikan pendapatan yang besar bagi petani sebagai bunga segar.

Penjual bunga segar mampu meningkatkan pendapatan yang pada akhirnya nanti akan mengangkat tingkat kesejahteraan kelompok penjual bunga segar (Pinaraswati \& Hendarto, 2018). Peningkatan Petani sebagai penyedia bunga segar diserahkan kepada pengepul poduk hasil pertanian berupa bunga pacar air yang diambil dari petani lansung menjualnya ke pasar (Suindari \& Surya, 2021). Bunga impatiens balsamina dapat dilihat pada Gambar 3.

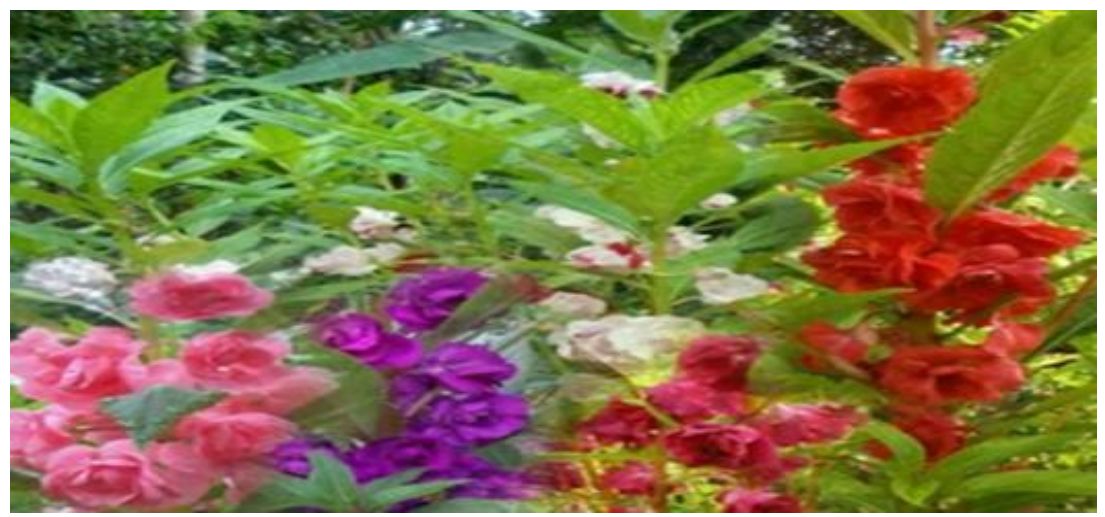

Gambar 3. Bunga siap di panen

Keberadaan bunga impatiens balsamina memberikan nilai tersendiri bagi petani yaitu sebagai sumber pendapatan untuk keluarga. Setiap petani mampu mengatur pola tanam sehingga dari segi agribisnis petani mampu menghasilkan setiap hari dan mampu memenuhi kebutuhan rumah tangga petani setiap hari.

Budidaya impaten balsamina tidak membutuhkan perawatan yang rumit. Dan tidak membutuhkan air sepanjang umur tanaman. Pemeliharaan dilakukan dengan pemupukan penggemburan dan penyiangan. Bunga ini dapat di panen setelah tanaman berumur 42 hari hingga tanaman berumur 3 bulan. Dan proses panen dapat dilakukan setiap hari. Budi daya tanaman ini tumbuh subur di tanah yang kaya akan hara dan gembur (Pramudita, 2014). Selain itu tanaman ini dapat juga dijadikan tanaman hias, tanaman budidaya dan tanaman obat (Khairiah et al., 2012).

Bunga impatien balsamina berwarna-warni ada yang putih, merah, ungu dan merah muda, menjadikan bunga ini mempunyai daya tarik sendiri dan mempunyai nilai ekonomis yang tinggi. Kelayakan usahatani tanaman pacar air sebesar Rp 1,64. Artinya bahwa setiap pengeluaran Rp 1, maka pendapatan usahatani tanaman bunga pacar air sebesar Rp 64 (Munir et al., 2021). Dengan nilai diatas 1,64 menandakan usahatani ini layak dijalankan. Beberapa faktor yang dapat menyebabkan inefisiensi teknis usahatani adalah pendidikan dan jumlah anggota rumah tangga. Semakin tinggi pendidikan petani maka tingkat inefisiensi teknis akan semakin rendah. Oleh karena itu, pengalaman menjadikan usahatani lebih efisien. Sedangkan peningkatan curahan tenaga kerja akan mengurangi nilai inefisiensi teknis. Dengan demikian, jumlah anggota rumah tangga yang besar mendorong efisiensi teknis dengan memastikan ketersediaan tenaga kerja dalam keluarga (Pande Komang Suparyana \& Sari, 2021). Dilihat dari sudut pandang agribinis famer's share dan marjin pemasaran dapat dilihat pada Tabel 1. 
Tabel 1. Famer's Share dan Marjin Pemasan Bunga Impatiens Balsamina

\begin{tabular}{|c|c|c|c|c|c|c|}
\hline Keterangan & Satuan & Petani & $\begin{array}{l}\text { Saluran I } \\
\text { Pengumpul } \\
\text { Desa }\end{array}$ & $\begin{array}{c}\text { Saluran II } \\
\text { Pengumpul } \\
\text { Pasar }\end{array}$ & $\begin{array}{c}\text { Saluran } \\
\text { III } \\
\text { Pengecer }\end{array}$ & Konsumen \\
\hline Jumlah Produk & $\mathrm{Kg}$ & 100 & & & & 100 \\
\hline Harga jual & $\mathrm{Rp}$ & 5,000 & 6,000 & 7,000 & 15,000 & 15,000 \\
\hline Plastik & $\mathrm{Rp}$ & & 500 & & & \\
\hline Pengangkutan & $\mathrm{Rp}$ & & 167 & 333 & 500 & \\
\hline Tenaga kerja & $\mathrm{Rp}$ & & 333 & 200 & 1,000 & \\
\hline retribusi & $\mathrm{Rp}$ & & & 1,000 & 1,000 & \\
\hline $\begin{array}{l}\text { Penerimaan } \\
\text { Biaya }\end{array}$ & $\mathrm{Rp} / \mathrm{Kg}$ & 500,000 & 6,000 & 7,000 & 15,000 & \\
\hline Pemasaran & $\mathrm{Rp} / \mathrm{kg}$ & & 1,000 & 2,033 & 3,500 & \\
\hline Keuntungan & $\mathrm{Rp} / \mathrm{kg}$ & 5,000 & 5,000 & 4,967 & 11,500 & 15,000 \\
\hline $\begin{array}{l}\text { Famer 's Share } \\
\text { Margine }\end{array}$ & $\%$ & & 120 & 140 & 300 & 300 \\
\hline $\begin{array}{l}\text { Pemasaran } \\
\text { Volume }\end{array}$ & $\mathrm{Rp}$ & & 1,000 & 2,000 & 10,000 & 10,000 \\
\hline Penjualan & & 100 & 100 & 100 & 100 & 1 \\
\hline $\begin{array}{l}\text { Penerimaan } \\
\text { Biaya }\end{array}$ & $\mathrm{Rp} / \mathrm{Kg}$ & 500,000 & 600,000 & 700,000 & $1,500,000$ & 15,000 \\
\hline Pemasaran & $\mathrm{Rp} / \mathrm{kg}$ & & 100,000 & 203,333 & 350,000 & \\
\hline Keuntungan & $\mathrm{Rp} / \mathrm{kg}$ & 5,000 & 500,000 & 496,667 & $1,150,000$ & 15,000 \\
\hline $\begin{array}{l}\text { Famer 's Share } \\
\text { Margine }\end{array}$ & $\%$ & & 100 & 99 & 230 & 300 \\
\hline Pemasaran & $\mathrm{Rp}$ & & 100,000 & 100,000 & 800,000 & 10,000 \\
\hline
\end{tabular}

Sumber: data primer tahun 2021

Hasil penelitian menunjukkan bahwa famer's Share sebesar 300\% jika petani langsung menjual kepada konsumen. Namun tersebut tidak memungkinkan dilakukan oleh petani secara mandiri, hal ini disebabkan oleh akses pemasaran yang dimiliki oleh masingmasing petani terbatas. Sehingga dengan mengikuti sistem pemasaran yang ada saat ini.

Marjin pemasaran tiap saluran pemasaran menunjukkan bahwa saluaran di tingkat pengecer memperoleh margine pemasaran yang paling besar, tetapi kemampuan pengecer menjual bunga impatien balsamina dalam jumlah terbatas setiap harinya. Marjin pemasaran yang diterima oleh saluran I dan saluran II lebih rendah dari saluran III dengan volume yang jauh lebih besar. Bahkan pada saluran II mampu memasarkan dalam jumlah yang paling besar. Perputaran produk yang terjadi antara petani pedagang dan konsumen terjadi setiap hari sehingga dapat mempercepat siklus perekonomian di pedesaan. Hal ini di sebabkan oleh petani mampu memasarkan bunga impatiens Balsamina setiap hari tanpa memikirkan produk yang dipasarkan tidak laku dipasaran karena produk tersebut dibayar langsung oleh pedagang pengumpul di tingkat desa

\section{Impatien Balsamina Sebagai Sarana Pelesatarian Budaya Lokal}

Budidaya impatien balsamina di Desa Sibang, sebagai tanaman pokok setelah padi. Pengembangan bunga ini memberikan kemudahan bagi masayarakat untuk membuat sarana upacara yang paling utama yang itu Canang Sari. 
Canang sari merupakan salah satu bentuk upakara yang dibuat dari janur sebagai sarana melakukan persembahyangan masyarakat Bali (Hariana, 2017). Canang sari merupakan banten yang amat penting, terlihat misalnya pada penggunaannya dalam ritual rutinitas keseharian orang Bali. Kajian secara genealogis menunjukkan bahwa canang sari merupakan banten hibriditas, yakni hasil kawin silang antara kultur pra-Hindu (Atmadja et al., 2015). Bunga sebagai bahan material dasar yang digunakan untuk membuat canang sari ini mengalami akulturasi dengan tradisi budaya setempat (Hariana, 2019).

Pembuatan sarana upacara sebagai identitas budaya local di Bali sangat kental dengan sarana dan prasarana berasal dari bunga. Menjadikan bunga impatiens balsamina sebagai produk yang utama dalam kehidupan masyarakat di Bali.

Hasil penelitian yang dilakukan kepada 10 orang konsumen yang membeli bunga menunjukkan bahwa rata-rata konsumen membutuhkan setengah $\mathrm{kg}$ bunga setiap hari diluar hari raya Umat Hindu yang ada. Bahkan kebutuhan tersebut akan meninggat jika terdapat hari raya Purnama, Tilem, Kajeng Kliwon apalagi pada saat hari Raya Galungan dan Kuningan.

Ketersediaan bunga impatien balsamina sangat penting khususnya masayarakat di perkotaan. Hal ini disebabkan masayarakat jarang menanam tanaman yang menghasilkan bunga untuk sarana upacara yang disebabkan faktor lahan yang sempit. Dengan adanya persediaan bunga memudahkan untuk membuat sarana upacara yang merupakan salah satu budaya yang selalu dijaga keberlangsungannya. Dan terus dipertahankan sebagai tradisi turun temurun oleh masayarakat Bali. Pada gambar 4 dapat dilihat penggunaan bunga sebagai sarana upacara bagi umat hindu di Bali.

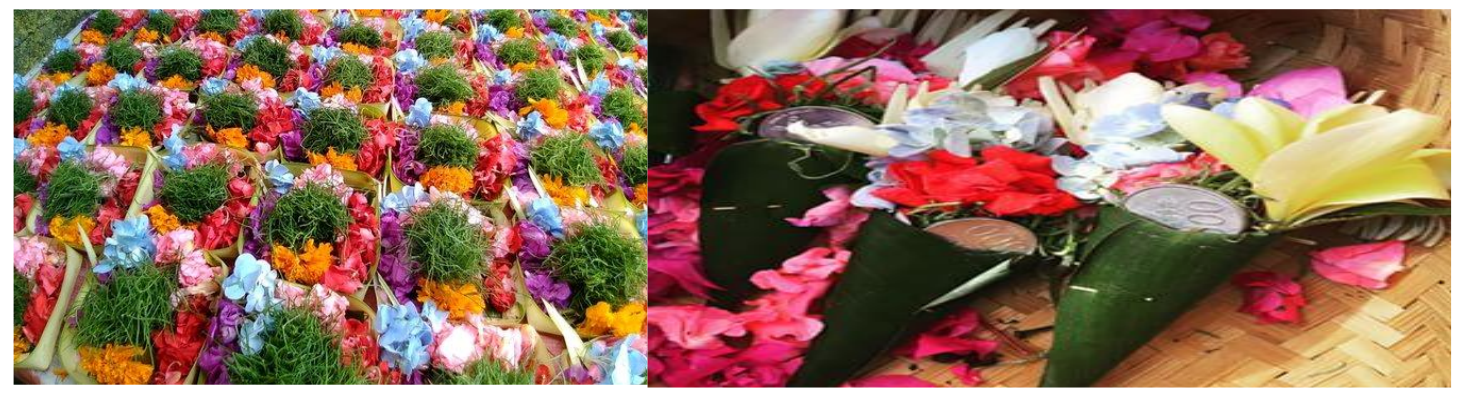

Gambar 4. Penggunaan bunga impatien balsamina sebagai sarana upacara

\section{Kesimpulan}

Hasil penelitian menunjukkan bahwa keuntungan agribinis bunga impatiens balsamina paling tinggi diperoleh oleh pelaku agribinis pada saluran III yaitu pengecer rata-rata sebesar Rp 11.500 per kg penjualan bunga. Famer's share yang dihasilkan dari penelitian menunjukkan bahwa share yang diterima petani rata-rata $120 \%$ jika petani menjual di pedagang pengumpul di Desa. Dan margine pemasaran yang diperoleh paling besar pada saluran pemasaran III. Bunga impatien balsamina sebagai sarana upacara dalam budaya lokal masyakarat. Saran yang diberikan kepada petani yaitu mencari alternatif agar mampu memasarkan langsung kepada konsumen agar penjualan yang diterima lebih besar. Dan bunga impatien balsamina dijadikan sebagai produk local unggulan, karena selain dapat dijadikan produk agribisnis dan sarana menjaga kelestarian budaya lokal

\section{Daftar Pustaka}

Aditya, I. M. J., Widyantara, I. W., \& Wijayanti, P. U. (2017). Pendapatan dan Risiko Produksi Usahatani Pacar Air (Impatiens balsamina Linn) pada Musim Hujan dan Kemarau di Subak Saradan, Desa Sibang Gede, Kecamatan Abiansemal, 
Kabupaten Badung. Jurnal Agribisnis Dan Agrowisata (Journal of Agribusiness and Agritourism), 6(1), 131-141. https://doi.org/10.24843/JAA.2017.V06.I01.P15 Atmadja, N. B., Atmadja, A. T., \& Maryati, T. (2015). Makna Porosan Pada Canang Sari Sebagai Banten Rutinitas Keseharian Pada Masyarakat Hindu di Bali. Seminar Nasional Riset Inovatif Ke-3, 319-324.

Hariana, K. (2017). Banten Canang Sari sebagai Identitas Budaya Bali dalam Pewarisan Pendidikan Estetika dan Ecoart di Sulawesi Tengah. Seminar Nasional Seni Dan Desain: "Membangun Tradisi Inovasi Melalui Riset Berbasis Praktik Seni Dan Desain,” 58-68. https://www.semanticscholar.org/paper/Banten-Canang-Sarisebagai-Identitas-Budaya-Bali-diHariana/5351f8a3f9a15e8e5bb9fb466a8167ab96a57b53

Hariana, K. (2019). Transit and Transition: Refleksi Multikultural pada Seni Sesaji Canang Sari di Sulawesi Tengah. Seminar Nasional Seni Dan Desain: "Reinvensi Budaya Visual Nusantara," 213-220.

Istiyanti, E. (2010). Efisiensi Pemasaran Cabai Merah Keriting Di Kecamatan Ngemplak Kabupaten Sleman. Jurnal Pertanian MAPETA, 12(2), 72-144. http://ejournal.upnjatim.ac.id/index.php/mapeta/article/view/213

Khairiah, N., Dahelmi, \& Syamsuardi. (2012). Jenis-Jenis Serangga Pengunjung Bunga Pacar Air (Impatiens balsamina Linn. :Balsaminaceae). Jurnal Biologi Universitas Andalas, 1(1), 9-14. https://doi.org/10.25077/JBIOUA.1.1

Lim, T. K. (2014). Edible Medicinal And Non-Medicinal Plants (Vols. 7, Flowers). Springer Dordrecht. https://doi.org/10.1007/978-94-007-7395-0

Munir, A. S., Hartanti, D. A. S., \& Qomariyah, S. N. (2021). Analisis Pendapatan Usahatani Tanaman Pacar Air Di Desa Trawasan Kecamatan Sumobito Kabupaten Jombang. Agrosaintifika: Jurnal Ilmu-Ilmu Pertanian, 3(2), 219-224. https://doi.org/10.32764/AGROSAINTIFIKA.V3I2.1759

Pinaraswati, S. O., \& Hendarto, T. (2018). PKM Kelompok Penjual Bunga Segar Di Pasar Kota Gresik Provinsi Jawa Timur. unitomo. http://repository.unitomo.ac.id/1538/

Pramudita, T. (2014). Isolasi Senyawa Flavonoid Dari Ekstrak Etanol Daun Pacar Air (Impatiens Balsamina L.) [Fakultas MIPA Universitas Islam Bandung (UNISBA)]. http://repository.unisba.ac.id:8080/xmlui/handle/123456789/4615

Pranadji, T. (2004). Kerangka Kebijakan Sosio-Budaya Menuju Pertanian 2025 ke Arah Pertanian Pedesaan Berdaya Saing Tinggi, Berkeadilan dan Berkelanjutan. Forum Penelitian Agro Ekonomi, $22(1), \quad 1-21$. https://doi.org/10.21082/FAE.V22N1.2004.1-21

Suindari, N. M., \& Surya, L. P. S. (2021). Dampak Pengembangan Obyek Wisata Kayu Putih Terhadap Keuangan Dan Aktivitas Ekonomi Masyarakat Di Banjar Bayan. JIMAT (Jurnal Ilmiah Mahasiswa Akuntansi) Undiksha, 12(3), 980-987. https://doi.org/10.23887/JIMAT.V12I3.40699

Suparyana, P K, Ramantha, W., \& Budiasa, W. (2017). Analisis Permintaan Buah Pisang Di Kota Denpasar, Bali. JURNAL MANAJEMEN AGRIBISNIS (Journal Of Agribusiness Management), 5(1), 33-44. https://doi.org/10.24843/JMA.2017.V05.I01.P04

Suparyana, Pande Komang, \& Sari, N. M. W. (2021). Analisa Keuntungan Budidaya Stroberi Berbasis Organik Di Desa Sembalun Lawang. DwijenAGRO, 11(1), 5156. http://103.207.99.162/index.php/dwijenagro/article/view/1091

Wulandari, D., Qurniati, R., \& Herwanti, S. (2018). Efisiensi Pemasaran Durian (Durio Zibethinus) di Desa Wisata Durian Kelurahan Sumber Agung. Jurnal Sylva Lestari, 6(2), 68-76. https://doi.org/10.23960/JSL2668-76 